\title{
Avaliação da trombólise arterial em animais deficientes em MAGP1 por microscopia Intravital.
}

\author{
Bárbara P. Gandur (IC), Cláudio C. Werneck (PQ), Cristina P. Vicente (PQ), Danielle P. Sousa (PG).
}

\section{Resumo}

Experimentos com animais deficientes em MAGP1 sugerem a importância deste componente no processo trombótico. Uma alternativa para amenizar os problemas causados pela trombose arterial é o uso de agentes trombolíticos, como exemplo o medicamento Actilyse, o qual se liga à fibrina, induzindo a conversão de plasminogênio em plasmina, promovendo a dissolução da fibrina do trombo. Assim, o objetivo do trabalho é o estabelecimento da técnica de trombólise arterial a partir da utilização do Actilyse.

Palavras Chave: Trombólise arterial, Actilyse, MAGP1.

\section{Introducão}

Diversos estudos têm demonstrado que a expressão de MAGP1 (componente da microfibrila) apresenta grande importância para o desenvolvimento vascular. Estudos mostram a importância deste componente no processo trombótico através da indução de trombo em animais deficientes em MAGP1. Uma maneira de amenizar os problemas causados pela trombose arterial é o uso de trombolíticos, como exemplo, o medicamento Actilyse.Tal fármaco é composto de uma glicoproteína, que ao ser administrada se liga à fibrina, promovendo a dissolução da fibrina do trombo.

O objetivo do presente trabalho é estabelecer a técnica de trombólise arterial assistida por microscopia intravital em animais selvagens e deficientes em MAGP1.

\section{Resultados e Discussão}

Foi visto que os animais deficientes em MAGP1 levam praticamente o dobro do tempo $( \pm 697,167$ segundos) para ter o vaso sanguíneo ocluído em relação aos animais selvagens $( \pm 381,167$ segundos).

Como controle do experimento, foi utilizado injeção de heparina (50uL) 10 min após a lesão (tempo previamente padronizado). Os resultados mostraram eficiência como controle devido ao aumento do tempo de oclusão $(n=6)$.

Já os resultados utilizando Actylise in vivo, (com injeção antes da cirurgia e 5 minutos após a formação do trombo) não apresentou aumento no tempo de oclusão do vaso tanto para camundongos selvagens como para os MAGP1.
Figura 1. Tempo de oclusão em animais selvagens e deficientes em MAGP1 sem medicação, com heparina e com Actilyse.

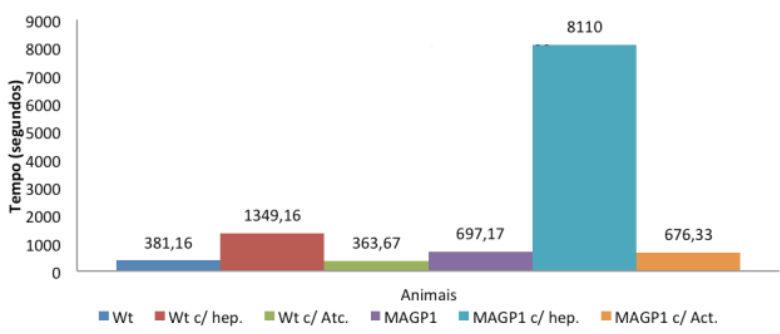

Para testar a eficácia do medicamento utilizado foi realizado um teste in vitro a partir de agregação plaquetária com sangue humano. Verificou-se a eficiência do medicamento através da diluição do trombo após 1 hora e 35 minutos, em banho a $37^{\circ} \mathrm{C}$, com $75 \mu$ le Actilyse, previamente padronizado $(n=5)$.

\section{Conclusões}

Os experimentos in vivo não foram conclusivos. No entanto, em experimentos in vitro com sangue humano obtivemos resultados. Uma das hipóteses seria que o medicamento utilizado é derivado de uma glicoproteína humana, assim não apresentou efeito em camundongos. Porém, não podemos esquecer a possibilidade da utilização de metodologia inadequada para comprovação da eficiência trombolítica do medicamento.

\section{Agradecimentos}

Agradeço à equipe do Laboratório de Fibras Elásticas e à instituição CNPq.

\footnotetext{
${ }^{1}$ Farrehi, P. M., C. K. Ozaki, et al. (1998). "Regulation of arterial thrombolysis by plasminogen activator inhibitor-1 in mice." Circulation 97 (10): 1002-1008..
} 